\title{
Sistem Water Level Otomatis Berbasis Mikrokontroler Dan Sms Gateway
}

\author{
Liza Safitri ${ }^{1}$, Novan Prasetyo ${ }^{2}$ \\ 1,2 Jurusan Teknik Informatika STT Indonesia Tanjungpinang \\ Jln. Pompa Air No. 28 Tanjungpinang Kepulauan Riau Indonesia \\ savetree3300@gmail.com ${ }^{1}$,novan.instagram@gmail.com ${ }^{2}$
}

\begin{abstract}
Intisari - Seiring dengan perkembangan zaman yang semakin pesat, kebutuhan akan efektifitas dan efesiensi sangat diutamakan dalam berbagai bidang. Hal tersebut telah mendorong manusia untuk berkreasi dan berinovasi dalam bidang teknologi untuk menciptakan suatu alat yang lebih efektif dan efesien. Perkembangan teknologi saat ini dapat dilihat sudah banyak alat yang diciptakan agar memberikan kemudahan pada masyarakat dalam melaksanakan pekerjaan sehari-hari. Ditambah dengan kebutuhan sistem yang semakin canggih dan makin banyak pula alat-alat komunikasi maupun alat bantu manusia yang harus kita kembangkan menjadi lebih efektif. Salah satu nya alat untuk pendeteksi air menggunakan SMS Gateway. Sistem ini dirancang dengan menggunakan Ultrasonic sensor sebagai water level dan SMS Gateway untuk memberikan pemberitahuan kepada pengguna tersebut bahwa air sudah mulai mencapai batas yang di tentukan dan arduino uno sebagai pusat kendali. Ketika air sudah mulai memasuki batasan ketinggian yang telah di tentukan maka alat ini akan berbunyi dan sms akan masuk ke pengguna dengan otomatis memberitahu bahwasannya air hampir mencapai batasan yang telah di tentukan, dan gerbang air akan terbuka otomatis.
\end{abstract}

Kata kunci : Arduino Uno, SMS Gateway, Mikrokontroler, Ultrasonic Sensor.

Abstract - Along with the development of the era which is going rapidly, the need for evectiveness and eviciency is more preferred in various fields. It has encouraged people to recreate and innovate in technology to create a tool which more effective and efficient. The development of technology at this time can be seen that already many tools which are created to provide convenience to the society in doing the daily work. Added with the needs of increasingly sophisticated systems and will also many tools of communication and human aids that we must develop become more effective. One of them is the tool for detection of water in using SMS Gateway. The tool was designed by using Ultrasonic Sensor as water level and SMS Gateway to give the notification to users that water has started to reach the specified limitsand aurduino as the control center. When the water has begin entering the height limit which has been specified so this tool will rang and the message will log in or up to the user by automatically notifying them that the water is almost reach the specified limit, and water gate opens automatically.

Keywords : Arduino Uno, SMS Gateway, Mikrokontroler, Ultrasonic.

\section{PENDAhuluan}

Seiring dengan kemajuan pola pikir sumber daya manusia yang semakin maju. Keinginan untuk selalu menciptakan suatu hasil karya mengalami perubahan secara bertahap yang bersifat kompetitif agar dapat menciptakan kemudahan bagi manusianya sendiri yang di dukung dengan perangkat perangkat canggih. Kondisi tersebut menginspirasi penulis selaku mahasiswa untuk menciptakan suatu produk yang bersifat ekonomis dan efisien dengan hasil yang bersifat kualitatif. Hal itu tidak akan tercapai apabila suatu industri masih menggunakan sistem manual yang mayoritas menggunakan jasa tenaga kerja manusia.

Contoh pada Bendungan membutuhkan pengukuran ketinggian debit air dan Dalam rumah tangga terkadang juga membutuhkan dalam pengukuran ketinggian air misalkan untuk mengetahui isi penampungan air yang dimiliki. Untuk memantau ketinggian air ini ada beberapa cara, dari cara tradisional dan cara modern. Sebelum ditemukannya suatu cara modern, manusia menggunakan semacam tongkat panjang atau galah untuk mendeteksi nilai ketinggian air. Cara tradisional ini memiliki kelemahan yaitu untuk mengukur tangki yang memiliki kedalaman yang cukup dalam akan mengalami kesulitan dan pengukuran dengan cara ini tidak dapat dilakukan secara terus menerus karena faktor keterbatasan fisik yang ada pada manusia.

Dengan metode modern yang memanfaaatkan teknologi ada beberapa cara untuk mengukur ketinggian air tersebut salah satunya yaitu dengan menanamkan sensor elektroda pada dinding penanpungan dengan jarak tertentu. Saat air menyentuh elektroda tersebut maka akan terdeteksi dengan sistem konduktifitas. Cara lainnya yaitu dengan menggunakan sensor ultrasonik yang di pasang di atas tangki. Sensor tersebut mendeteksi jarak dari sensor ke permukaan air sehingga pendeteksian tidak perlu dilakukan dengan kontak fisik antara sensor dengan permukaan air.

Dari kedua cara tersebut yang paling efektif adalah menggunakan sensor ultrasonik untuk pendeteksiannya. Dengan sensor ultrasonik tersebut tingkat pendeteksian akan menunjukkan hasil yang lebih akurat dan ketelitian yang tinggi. Disini muncul permasalahan baru yaitu perangkat tersebut tidak dapat digunakan secara universal karena hanya dapat digunakan untuk tangki yang sejenis, apabila alat tersebut dipindahkan ke penampungan yang dimensinya berbeda tentunya harus melakukan konfigurasi yang sangat sulit dan memerlukan perancangan sistem yang baru.

Faktor keamanan dan keselamatan merupakan faktor yang penting juga dalam sistem ini. Dibutuhkan sebuah sistem yang 
dapat memberitahukan adanya informasi terkait akan adanya kejadian, dapat berupa bencana maupun berisikan tentang prediksi. Salah satu alternatifnya adalah menggunakan fasilitas SMS. SMS merupakan fasilitas standar dari Global System for Mobile (GSM). Fasilitas ini dipakai untuk mengirim dan menerima pesan. Mengingat pada masa sekarang hampir semua orang memiliki telepon genggam sebagai alat komunikasi.

Selain mudah digunakan, SMS juga merupakan cara yang cepat untuk menyampaikan informasi peringatan dini. Teknologi SMS saat ini juga sudah mengalami perkembangan baik dari segi fungsi maupun penggunaan. Salah satu teknologi SMS yang sedang berkembang saat ini dan digunakan oleh berbagai perusahaan, lembaga serta instansi adalah Sms gateway. Sms gateway merupakan sebuah sistem yang digunakan oleh penyedia jasa untuk mengirim maupun menerima SMS secara otomatis. Sms gateway tidak memerlukan koneksi internet manapun karena sifatnya memang bekerja sendiri. Oleh karena itu, dibutuhkanlah sistem informasi yang berbasis SMS

Gateway yang efektif dan efesien untuk menyampaikan informasi peringatan dini kepada masyarakat melalui Pesan singkat dan instansi terkait, agar dapat menerima informasi peringatan dini dengan cepat dan tepat.

Berdasarkan uraian latar belakang dan beberapa malasah diatas, penulis tertarik untuk melakukan penelitian dengan judul "Sistem Water level Otomatis Berbasis Mikrokontroler \& Sms gateway".

\section{Metodologi Penelitian}

\section{A. Metode Pengumpulan Data}

Dalam pelaksanaan kegiatan pengumpulan data yang menjadi dasar dan untuk melengkapi laporan skripsi ini, maka digunakan teknik yang umum dalam kegiatan ilmiah, yaitu:

1. Observasi yaitu metode pengumpulan data yang kompleks karena melibatkan berbagai faktor dalam pelaksanaannya. Metode pengumpulan data observasi tidak hanya mengukur sikap dari responden, namun juga dapat digunakan untuk merekam berbagai fenomena yang terjadi. Teknik pengumpulan data observasi cocok digunakan untuk penelitian yang bertujuan untuk mempelajari perilaku manusia, proses kerja, dan gejalagejala alam. Metode ini juga tepat dilakukan pada responden yang kuantitasnya tidak terlalu besar.

2. Studi literatur, yaitu pengumpulan data dengan cara mengumpulkan literatur paper dan bacaan-bacaan yang ada kaitannya dengan judul penelitian.

\section{B. Metode Pengembangan Perangkat Lunak}

Metode pengembangan perangkat lunak ini menggunakan model Waterfall (Classic Life Cycle) yang menyarankan pengembangan perangkat lunak secara sistematik dan berurutan yang dimulai dari tingkatan sistem tertinggi dan berlanjut ke tahap analisis kebutuhan, desain sistem, penulisan kode program, pengujian dan penerapan program/pemeliharaan. Kelebihan dari metode ini adalah terstruktur, dinamis, dan sequential.

\section{LANDASAN TEORI}

\section{A. Kebutuhan Perangkat Keras}

\section{Mikrokontroler ATMega 328}

ATMega 328 adalah mikrokontroler keluaran atmel yang mempunyai arsitektur RISC (Reduce Instruction Set Computer) yang mana setiap proses eksekusi data lebih cepat dari pada arsitektur CISC (Completed Instruction Set Computer). Mikrokontroler ini memiliki beberapa fitur antara lain:

a. Memiliki EEPROM (Electrically Erasable Programmable Read Only Memory) sebesar 1KB sebagai tempat penyimpanan data semi permanen karena EEPROM tetap dapat menyimpan data meskipun catu daya dimatikan.

b. Memiliki SRAM (Static Random Access Memory) sebesar $2 \mathrm{~KB}$.

c. Memiliki pin $\mathrm{I} / \mathrm{O}$ digital sebanyak 14 pin 6 diantaranya PWM (Pulse Width Modulation) output.

d. $32 \times 8$-bit register serba guna.

e. Dengan clock $16 \mathrm{MHz}$ kecepatan mencapai 16 MIPS.

f. 32 KB Flash memory dan pada arduino memiliki bootloader yang menggunakan $2 \mathrm{~KB}$ dari flash memori sebagai bootloader.[1].

\section{Arduino R3}

Arduino adalah pengendali mikro single-board yang bersifat open-source, diturunkan dari Wiring platform, dirancang untuk memudahkan penggunaan elektronik dalam berbagai bidang. Selain hardware-nya yang bersifat open source, Arduino juga menyediakan software yang digunakan untuk memprogram Arduino board secara gratis (open source).[2]

Arduino juga sudah banyak dipakai oleh perusahaan besar, contohnya Google menggunakan Arduino untuk Accessory Development Kit, NASA memakai Arduino untuk prototyping, dan Large Hadron Colider memakai Arduino dalam beberapa hal untuk pengumpulan data. Arduino menggunakan bahasa $\mathrm{C}$, yang sudah disederhanakan.

Pada pembahasan ini akan difokuskan pada salah satu dari Arduino yang beredar tersebut, yaitu Arduino Uno. Jenis yang ini adalah yang paling banyak digunakan. Versi yang terakhir adalah Arduino Uno R3 (Revisi 3), menggunakan ATMega 328 sebagai mikrokontrollernya, memiliki 14 pin I/O digital dan 6 pin input analog. Untuk pemograman cukup menggunakan koneksi USB type A to To type B.

\section{Lampu LED (Light Emitting Diode)}

Lampu LED (Light Emitting Diode) adalah suatu lampu indikator dalam perangkat elektronika yang biasanya memiliki fungsi untuk menunjukkan status dari perangkat elektronika tersebut. Misalnya pada sebuah komputer, terdapat lampu LED power dan LED indikator untuk processor, atau dalam monitor terdapat juga lampu LED power dan power saving. Lampu LED terbuat dari plastik dan dioda semikonduktor yang dapat menyala apabila dialiri tegangan listrik rendah (sekitar 1.5 volt $D C$ ). Bermacam-macam warna dan bentuk dari lampu LED, disesuaikan dengan kebutuhan dan fungsinya.[3] 


\section{Buzzer}

Buzzer adalah sebuah komponen elektronika yang berfungsi untuk mengubah getaran listrik menjadi getaran suara. Pada dasarnya prinsip kerja buzzer hampir sama dengan loud speaker, jadi buzzer juga terdiri dari kumparan yang terpasang pada diafragma dan kemudian kumparan tersebut dialiri arus sehingga menjadi elektromagnet, kumparan tadi akan tertarik ke dalam atau keluar, tergantung dari arah arus dan polaritas magnetnya, karena kumparan dipasang pada diafragma maka setiap gerakan kumparan akan menggerakkan diafragma secara bolak-balik sehingga membuat udara bergetar yang akan menghasilkan suara.[4] Buzzer biasa digunakan sebagai indikator bahwa proses telah selesai atau terjadi suatu kesalahan pada sebuah alat (alarm)

\section{Motor Stepper}

Motor stepper adalah jenis motor yang putarannya dikontrol dengan cara yang khusus, yaitu dengan menghidupkan dan mematikan motor dengan pola tertentu. Berbeda dengan motor DC dan motor servo, motor stepper mampu mempertahankan posisinya walaupun tidak ada listrik.[5]

\section{Modul Gsm}

SIM900A adalah modul SIM yang digunakan pada penelitian ini. Modul SIM900 GSM/GPRS adalah bagian yang berfungsi untuk komunikasi antara kontroler Arduino dengan Web Service. Modul komunikasi GSM/GPRS menggunakan core IC SIM900A. Modul ini mendukung komunikasi dual band pada frekuensi 900 / $1800 \mathrm{MHz}$ (GSM900 dan GSM1800) sehingga fleksibel untuk digunakan bersama kartu SIM dari berbagai operator telepon seluler di Indonesia

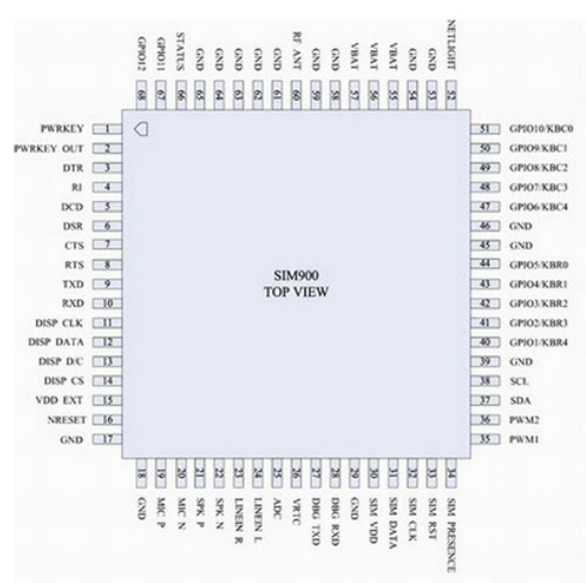

Gambar 1. Layout Dan Pin-pin Dari Modul Sim900A. [6]

\section{Sensor Ultrasonic}

Sensor adalah suatu piranti yang digunakan untuk melakukan suatu pengamatan terhadap suatu rangsangan dan mengubahnya ke dalam bentuk isyarat sehinggan bisa diukur. Rangsangan dapat berupa akustikk, elektrik, magnetik, optik, termal, maupun mekanik.[7]
Sensor ultrasonik adalah sebuah sensor yang berfungsi untuk mengubah besaran fisis atau bunyi menjadi besaran listrik dan sebaliknya. Cara kerja sensor ini didasarkan pada prinsip dari pantulan suatu gelombang suara sehingga dapat dipakai untuk menafsirkan eksistensi atau jarak suatu benda dengan frekuensi tertentu. Disebut sebagai sensor ultrasonik karena sensor ini menggunakan gelombang ultrasonik atau bunyi ultrasonik.

Gelombang ultrasonik adalah gelombang bunyi yang mempunyai frekuensi sangat tinggi yaitu $20.000 \mathrm{~Hz}$. Bunyi ultrasonik tidak dapat di dengar oleh telinga manusia. Bunyi ultrasonik dapat didengar oleh anjing, kucing, kelelawar, dan lumba-lumba. Bunyi ultrasonik bisa merambat melalui zat padat, cair dan gas. Reflektivitas bunyi ultrasonik di permukaan zat padat hampir sama dengan reflektivitas bunyi ultrasonik di permukaan zat cair. Akan tetapi, gelombang bunyi ultrasonik akan diserap oleh tekstil dan busa

\section{B. Gambaran Umum Sistem}

Sistem water level otomatis berbasis mikrokontroler dan sms gateway ini merupakan pendeteksi air dan pembuka pintu bendungan yang dapat membuka secara otomatis ketika level air saat menyentuh sensor [6]. Ketika keadaan masing-masing level, pintu akan terbuka sedikit demi sedikit dan modul gsm akan secara otomatis mengirim sms otomatis ke nomer telepon tujuan sesuai keadaan masing-masing level, sensor ultrasonic menyala hanya jika terdeteksi ada air yang menyentuh batas sensor. Namun ketika keadaan air sudah pada level paling bawah (kodisi aman) pintu akan tertutup secara otomatis.

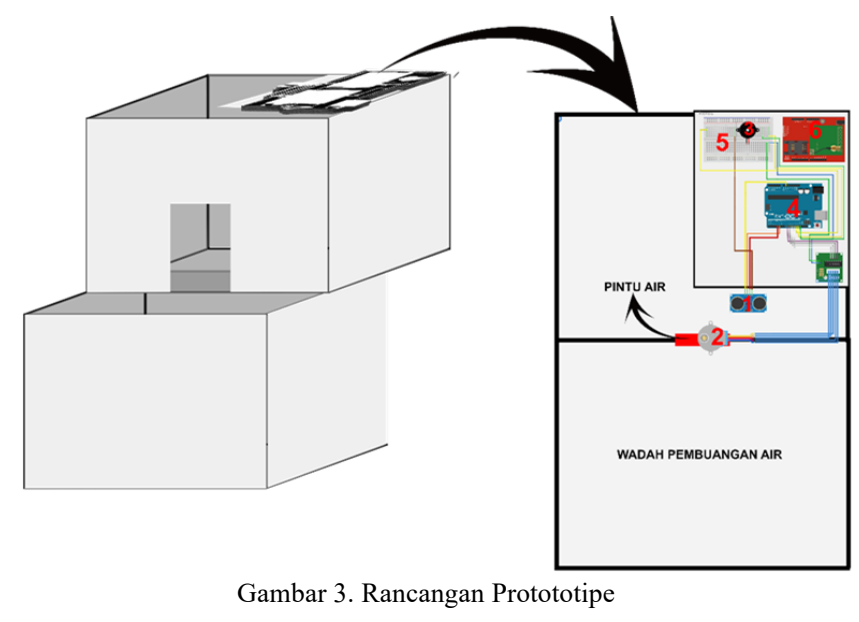




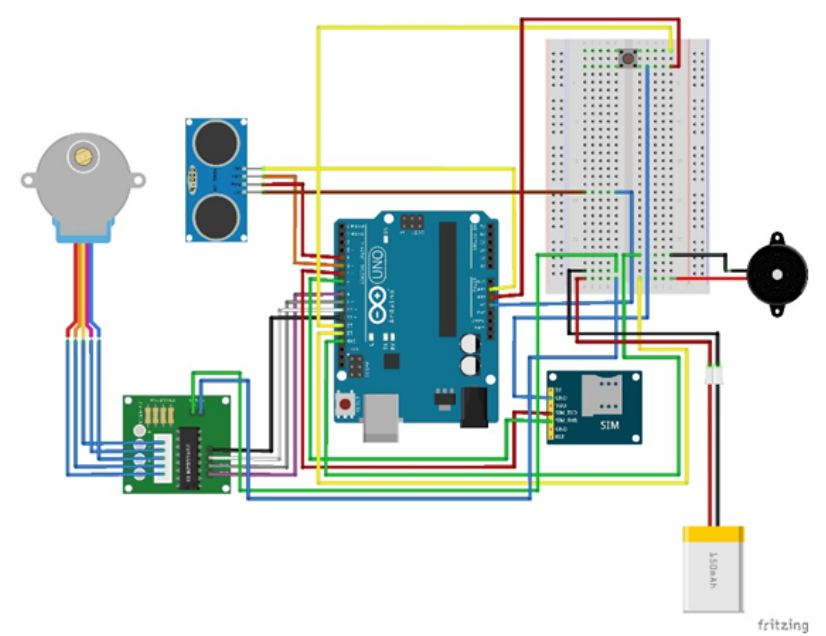

Gambar 4.Rancangan Skema Rangkaian

Keterangan gambar :

1. Ultrasonic sensor

Ultrasonic sensor pada sistem ini di gunakan sebagai pendeteksi air, untuk mendeteksi antara tinggi dan rendahnya air, sensor ultrasonic adalah komponen pertama yang bekerja pada sistem ini

2. Motor stepper

Motor stepper pada sistem ini di gunakan sebagai pembuka pintu seperti katrol, kemudian akan membuka pintu semakin lebar di setiap level airnya dan motor otomatis berputar melwan arah untuk menutup kembali pintu ketika air surut.

3. Buzzer

Buzzer pada sistem ini digunakan sebagai komponen OUTPUT yang berupa suara, jika sensor ultrasonic mendetaksi adanya air disetiap menyentuh level maka buzzer akan menerima data dari ATMega 328 dan di diterjemahkan menjadi suara beep satu kali.

4. Arduino R3 ATMega 328

Ardiuno R3 ATMeega328 pada sistem ini di gunakan sebagai komponen proses data, di mana setiap aktifitas input maupun output data akan di proses terlebih dahulu oleh Arduino R3 ATMega 328.

5. BreadBoard

BreadBoard pada sistem ini di gunakan sebagai komponen penghubung atau jumper antara arduino dengan komponen lainnya seperti sensor dan lain-lain.

6. GSM Shield

GSM Shield pada sistem ini di gunakan sebagai media pesan singkat (SMS) untuk memberitahukan informasi level air ke nomer telepon yang sudah di program.

Cara kerja sistem keseluruhan.

1. ATMega 328 membaca tinggi air melalui sensor Ultrasonic, apakah ketinggian air sudah menyentuh sensor? Jika sudah maka proses akan berlanjut

2. ATMega 328 membaca level air melalui sensor Ultrasonic, apakah sudah pada posisi level 1, 2 atau 3 ? jika sudah maka proses akan berlanjut ke Motor stepper otomatis akan membuka pintu air secara bertahap.

3. Setelah data level air di terima oleh ATMega 328 selanjutnya ATMega 328 akan memproses data tersebut yang nantinya di tujukan ke GSM Shield dan Buzzer, kedua komponen tersebut ialah komponen output :

a. Output GSM Shield berupa info sms berupa status level air

b. Output buzzer berupa suara beep jika sensor Ultrasonic dan Motor stepper mendeteksi adanya level air dan proses pintu air terbuka.

\section{Kebutuhan Perancangan}

1. Perangkat Keras

Kebutuhan perangkat keras yang digunakan untuk membangun prototipe ini dapat dilihat pada Tabel 4.1 pada tabel tersebut terdapat beberapa komponen perangkat keras yang memiliki fungsi sebagai komponen input, komponen output, dan sebagai power supply.

TABEL I

KEBUTUHAN PERANGKAT KERAS

$\begin{array}{cc}\text { Nebutuhan Perangkat Keras } & \text { Fungsi } \\ \text { (Hardware) } & \end{array}$

$1 \quad$ Arduino UNO R3, (Board

Mikrokontroler ATMega 328)

Proses

2

Ultrasonic sensor

Input

3

Motor stepper

Output

4

GSM shield

Output

5

Buzzer

Output

6

Breadboard

Portable

Board

7

Kabel Jumper

Konektor

8

Kabel USB

Konektor

9

PC (Personal Computer)

Power Supply

2. Perangkat Lunak

Adapun kebutuhan perangkat lunak yang digunakan untuk memprogram mikrokontroler. Berikut pada tabel kebutuhan perangkat lunak yang digunakan peneliti yaitu : 
TABEL II KEBUTUHAN PERANGKAT LUNAK

No Perangkat Lunak $\quad$ Fungsi

1 Arduino IDE Memprogram mikrokontroler

$2 \quad$ Fritzing $\begin{gathered}\text { Membangun skema } \\ \text { rangkaian dari protipe }\end{gathered}$

\section{Perancangan Sistem}

Perancangan sistem adalah tahap selanjutnya setelah analisa sistem, mendapatkan gambaran dengan jalan tentang apa yang dikerjakan pada analisa sistem. Perancangan sistem meliputi perancangan diagram konteks, flowchart, diagram blok rangkaian, perancangan bentuk prototipe, dan perancangan skematik rangkaian, perancangan bentuk prototipe, dan perancangan coding sistem.

1. Perancangan Coding Sistem

Perancangan Coding adalah perancangan yang menggambarkan fungsi masing-masing coding yang diprogram pada ATMega 328. Kutipan Coding ini akan menggambarkan fungsi keseluruhan input dan output sistem. Berikut perancangan Coding Sistem water level otomatis berbasis mikrokontroler dan sms gateway dapat dilihat Gambar dibawah ini :

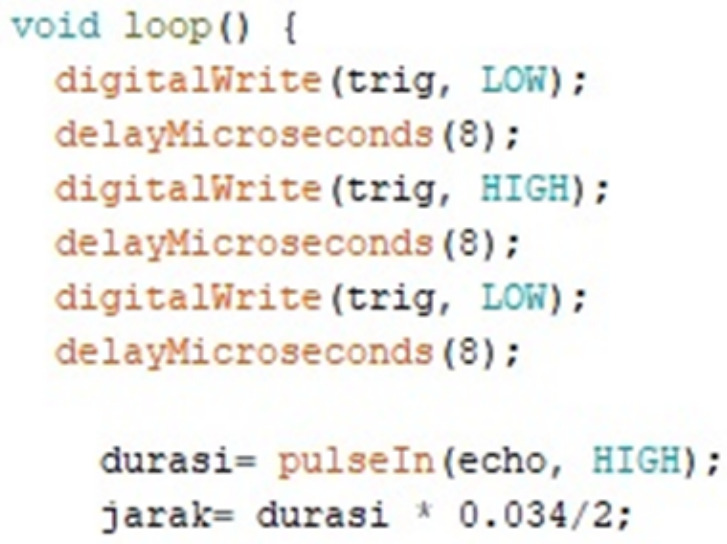

Gambar 5. Coding Sensor Ultrasonik

Pada gambar berkotak merah, fungsi dari coding di atas sebagai kondisi dari sensor ultrasonic, jika kondisi terpenuhi maka program akan melanjutkan ke pernyataan-pernyataan tertentu, seperti pada gambar diatas.

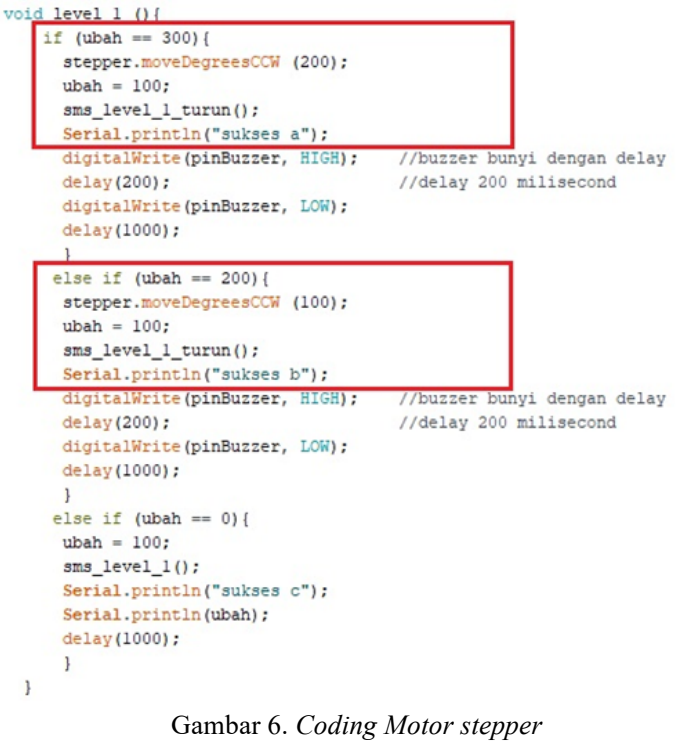

Pada gambar berkotak merah, fungsi dari coding diatas sebagai kondisi dari Motor stepper jika kondisi terpenuhi maka program akan melanjutkan ke pernyataan-pernyataan tertentu, seperti pada gambar di atas

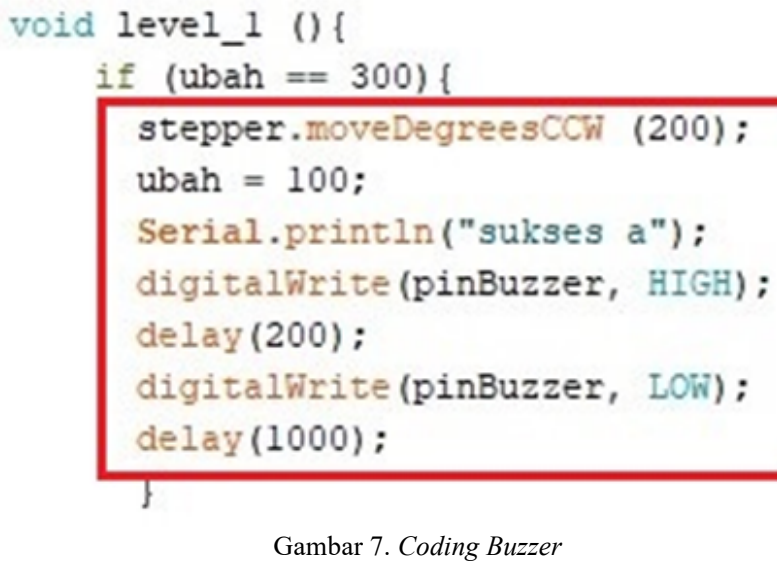

Gambar 7. Coding Buzzer

Pada gambar berkotak merah, fungsi dari coding diatas untuk menghidupkan buzzer, jika sensor Ultrasonic mendeteksi adanya ketinggian air maka kondisi buzzer akan menerima data dan diterjemahkan oleh suara beep selama 0.2 detik

Gambar 8. Coding Tombol Kalibrasi Ulang 
Pada gambar, fungsi dari coding diatas untuk mengkalibrasi ulang putaran motor stepper ke posisi awal, jika terkandala saat membuka pintu air

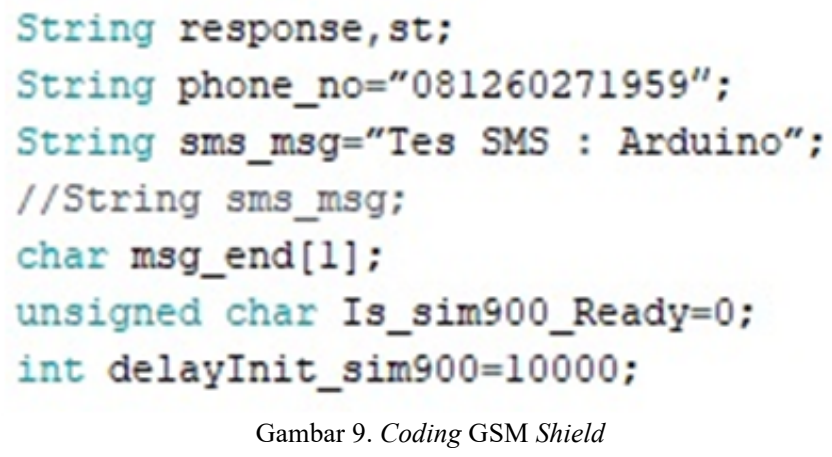

Gambar 9. Coding GSM Shield

Pada gambar di atas, fungsi dari coding diatas untuk mengirim sms pemberitahuan ke nomer telepon tujuan jika air menyentuh sensor ultrasonic pada setiap level.

\section{E. Flowchart}

Perancangan flowchart sistem merupakan perancangan terhadaap urutan proses secara mendetail dan hubungan antar proses atau instruksi dengan proses lainnya dalam suatu system [8]. Berikut ini adalah gambar flowchart sistem secara keseluruhan pada prototipe Sistem water level otomatis berbasis mikrokontroler dan sms gateway.

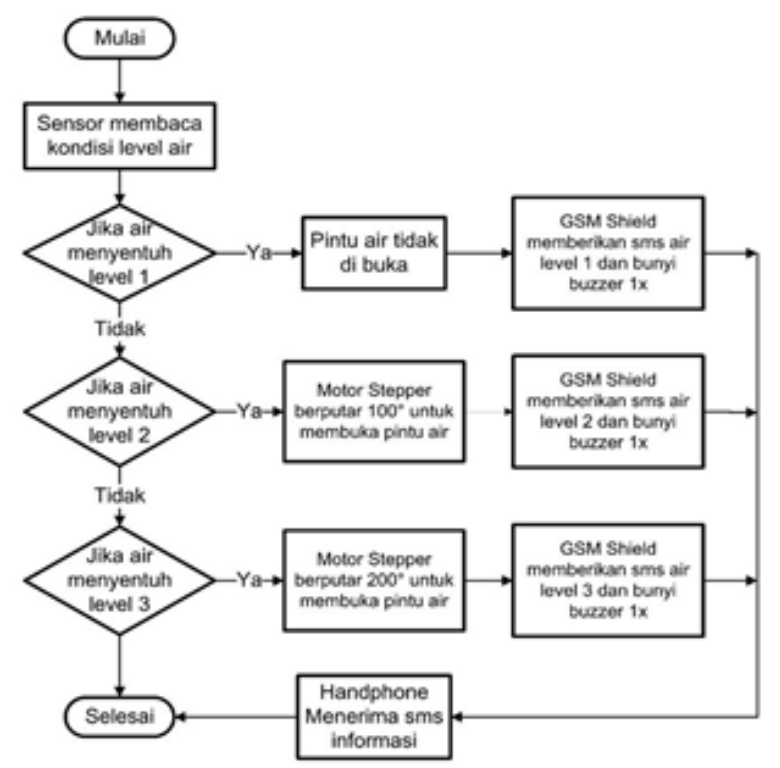

Gambar 10. Flowchart Sistem Secara Keseluruhan

\section{F. Diagram Konteks}

Perancangan diagram konteks adalah perancangan yang menggambarkan proses dan ruang lingkup sistem. Diagram konteks ini akan menggambarkan keseluruhan input dan output sistem. Berikut perancangan diagram konteks prototipe
Sistem water level otomatis berbasis mikrokontroler dan sms gateway dapat dilihat Gambar dibawah ini :

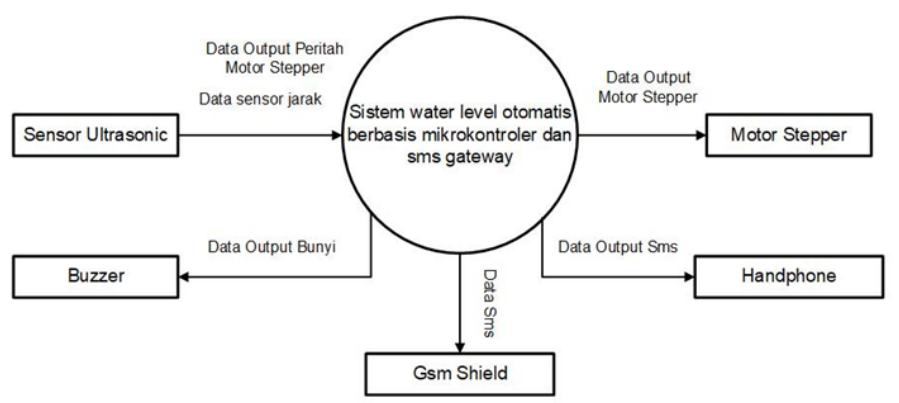

Gambar 11. Perancangan Diagram Konteks

\section{G. Data Flow Diagram (DFD)}

Perancangan data flow diagram adalah penggambaran arus data dari sistem. Berikut Gambar 11 pada perancangan data flow diagram (DFD) prototipe Sistem water level otomatis berbasis mikrokontroler dan sms gateway.

Data Flow Diagram (DFD) adalah diagram yang digunakan untuk menggambarkan suatu sistem yang sudah jadi atau sistem yang baru dirancang yang akan dikembangkan secara logika, tanpa mempertimbangkan lingkungan fisik kemana data tersebut disimpan[9]. Disamping itu ada Data flow Diagram (DFD) juga dapat menggambarkan arus data yang terstruktur dan jelas dari mulai pengisian data sampai dengan keluarannya.

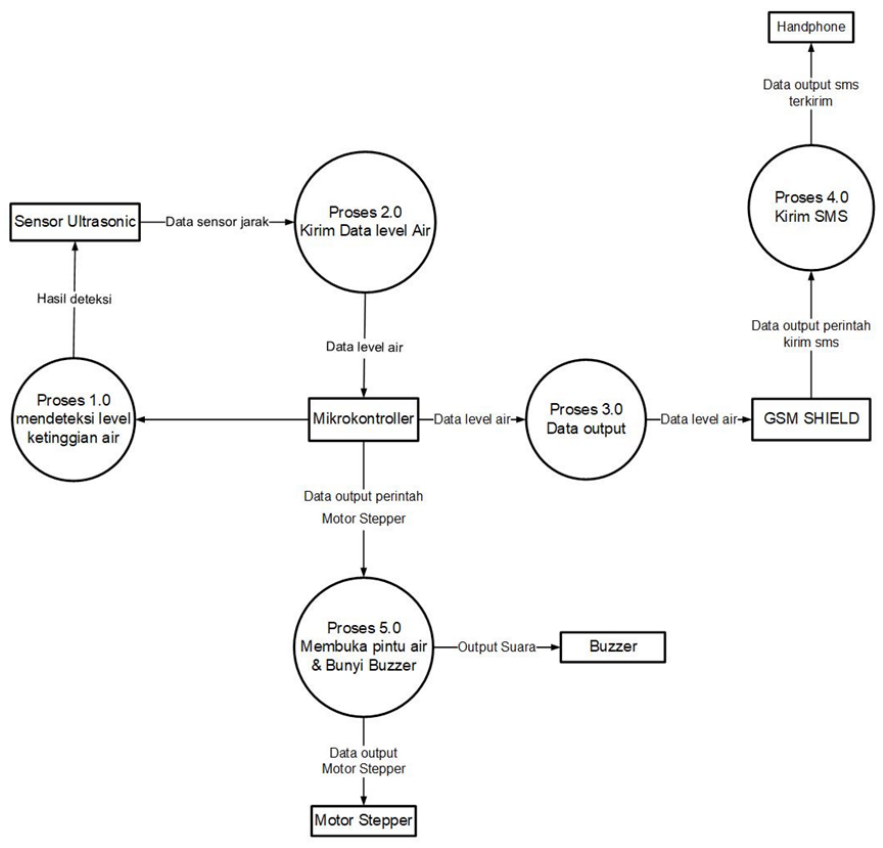

Gambar 12. Data Flow Diagram

Berikut penjelasan flowchart cara kerja sistem pengendalian waterlevel berbasis mikrokontroler :

1. Mulai adalah kondisi awal sistem.

2. Sensor ultasonic standby ketika membaca kondisi level air 
3. Ketika air menyentuh level 1, pintu air tidak terbuka karena kondisi level air masih aman lalu GSM Shield mengirim sms air keadaan level 1 serta bunyi buzzer $1 \mathrm{x}$.

4. Ketika air menyentuh level 2, motor stepper berputar $100^{\circ}$ untuk membuka pintu air,GSM Shield mengirim sms air keadaan level 2 serta bunyi buzzer $1 \mathrm{x}$.

5. Ketika air menyentuh level 3, motor stepper berputar $200^{\circ}$ untuk membuka pintu air,GSM Shield mengirim sms air keadaan level 3 serta bunyi buzzer 1x.

6. Proses selesai.

\section{H. Skema Diagram}

Rancangan prototipe yang berguna untuk menjelaskan konfigurasi alur pin dari masing-masing alat yang terhubung

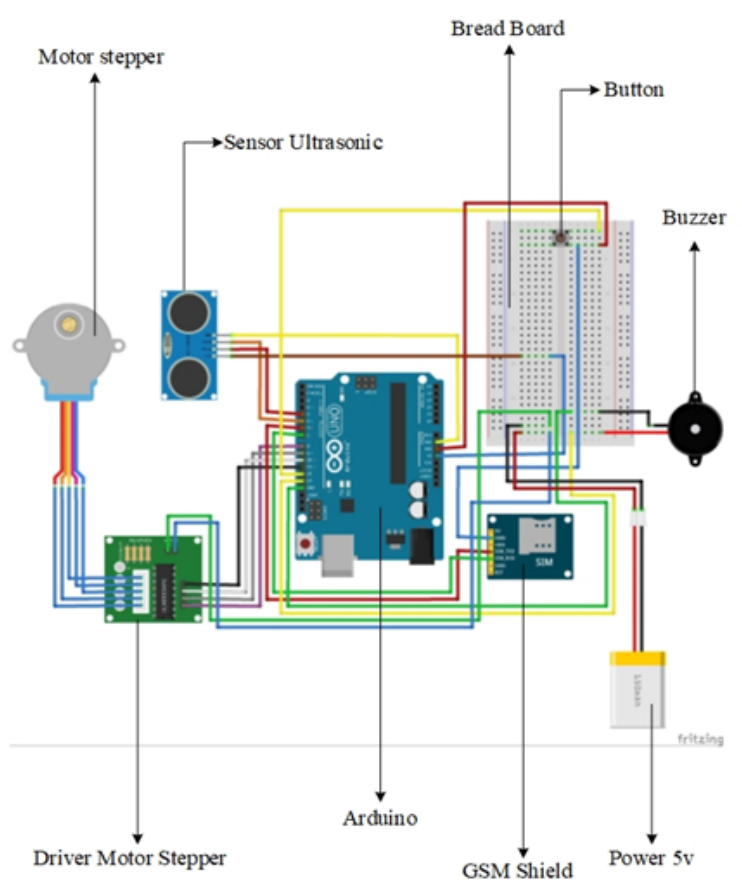

Gambar 13. Diagram Skema

\section{Pereancangan Diagram Blok Rangkaian}

Rancangan diagram blok rangkaian menggambarkan rancangan komponen dan alat yang digunakan pada sistem. Dilihat pada gambar 13 terdapat beberapa bagian utama, yaitu bagian proses, bagian input, bagian output, dan bagian power supply.

Pada bagian pertama terdapat komponen yang sangat penting pada sistem yang berfungsi sebagai eksekutor terhadap semua perintah pada sistem, yaitu sebuah Arduino Uno R3 yang terdapat mikrokontroler ATMega328. Bagian kedua adalah bagian input. Bagian ini merupakan bagian yang menjadi masukan terhadap sistem. Bagian input terdiri dari Sensor Ultrasonic. Bagian ketiga adalah bagian output. Bagian ini merupakan bagian yang menjadi keluaran (output) pada sistem. Bagian output terdiri dari GSM Shield, Motor stepper dan Buzzer. terdapat power supply tambahan pada motor stepper dan gsm shield menggunakan adapter 5v agar sistem dapat bekerja dengan baik. Selain itu bagian ini juga berfungsi untuk melakukan proses pengkodean sebelum sistem siap digunakan. Bagian ketiga ini terdiri dari sebuah laptop (PC). Perancangan diagram block rangkaian dapat dilihat pada gambar sebagai berikut:
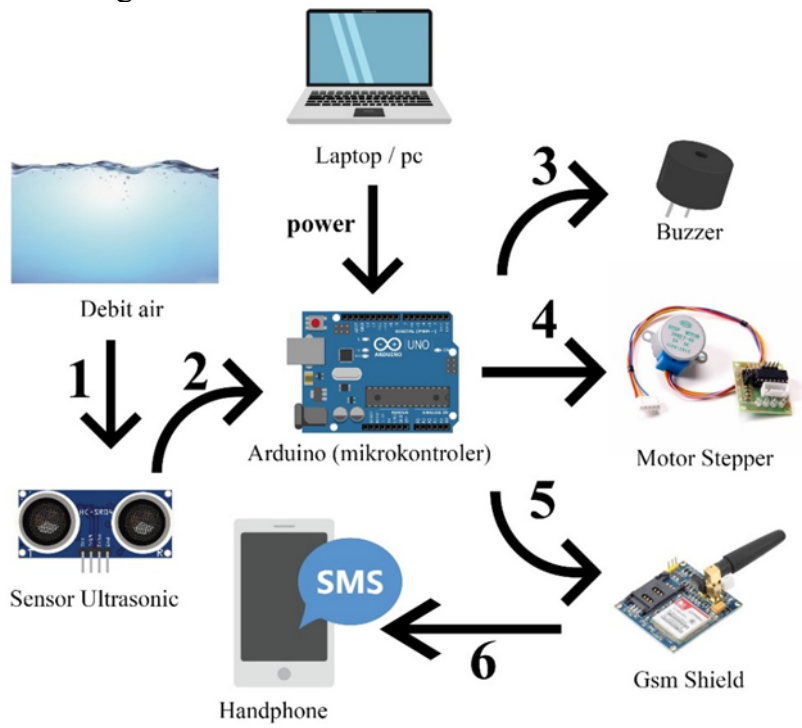

Gambar 14. Diagram Blok Rangkaian

J. Implementasi

1. Implementasi Tansmisi Data Arduino

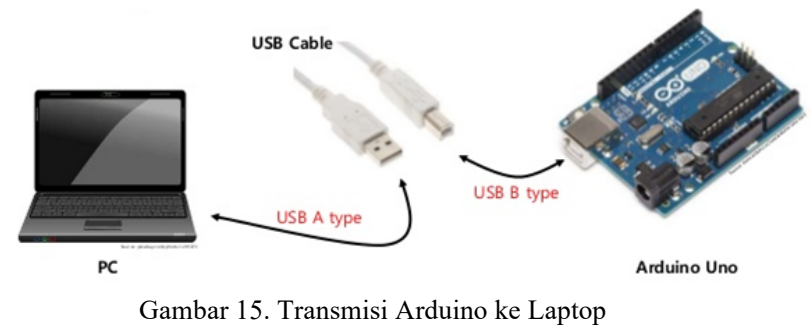

2.Implementasi Transmisi Data Gsm Shield Ke Handphone

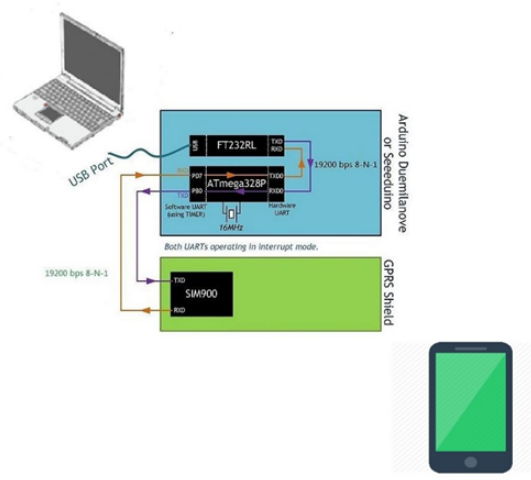

Gambar 16. Transmisi Data Gsm Shield ke Handphone 
2. Implementasi Rangkaian Sensor Ultrasonic

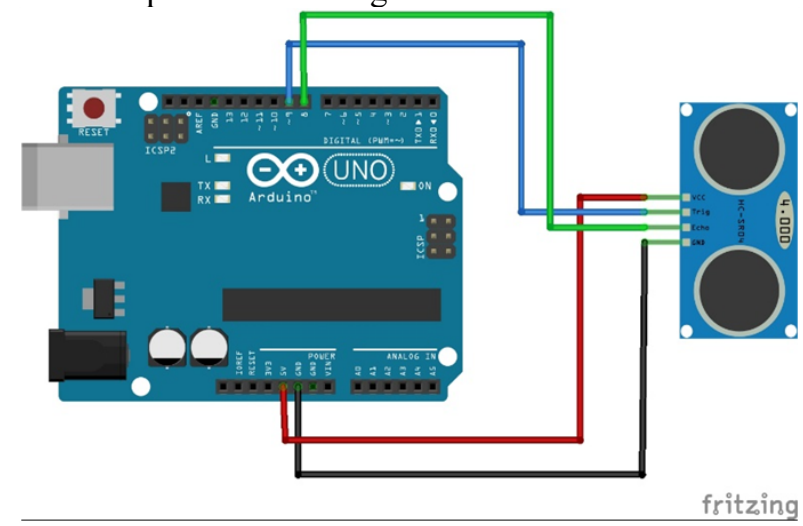

Gambar 17. Rangkaian Implementasi Sensor Ultrasonik

TABEL III

JALUR SENSOR ULTRASONIC MENUJU ARDUINO UNO R3

\begin{tabular}{cc}
\hline Pin Sensor Ultrasonic & Pin Arduino Uno R3 \\
\hline VCC & $5 \mathrm{~V}$ \\
$G N D$ & $G N D$ \\
TRIG & DIGITAL IN 9 \\
ECHO & DIGITAL IN 8 \\
\hline
\end{tabular}

3. Implementasi Motor Stepper

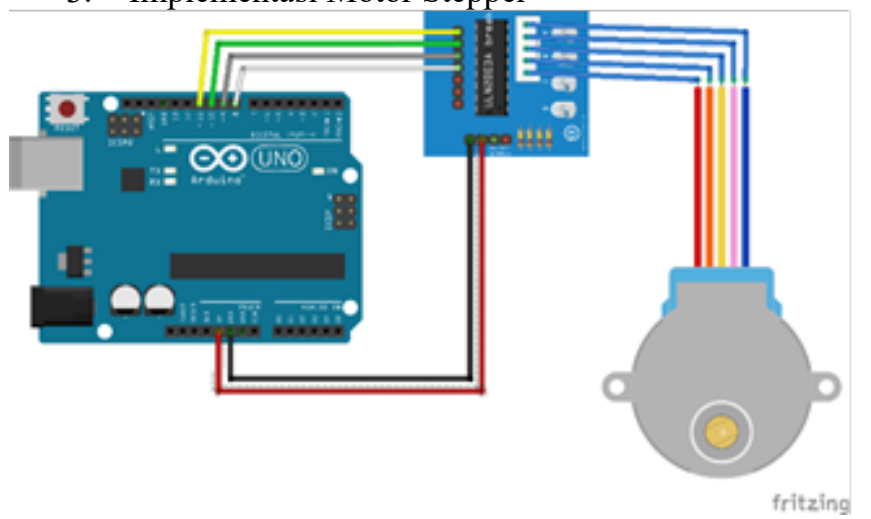

Gambar 18. Rangkaian Implementasi Motor stepper

TABEL IV

JALUR MOTOR STEPPER MENUJU ARDUINO UNO R3

Pin LDR Sensor

Pin Arduino Uno R3

$\mathrm{VCC}$

$G N D$

IN 1

DIGITAL IN 11

IN 2

DIGITAL IN 10

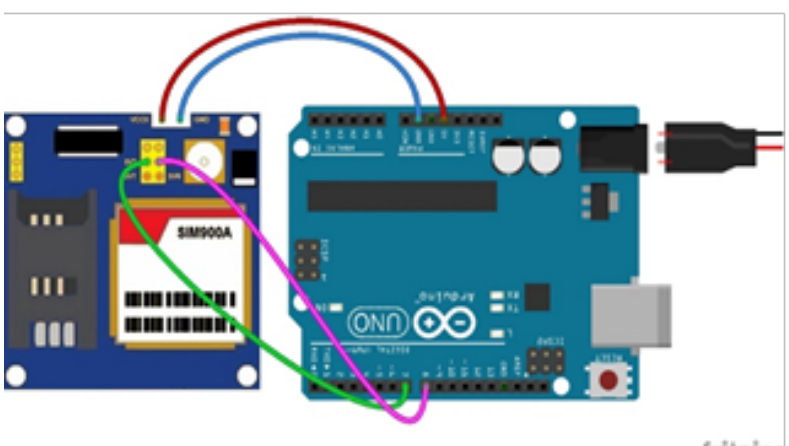

Gambar 19. Rangkaian Implementasi Gsm Shield

fritzing

TABEL V

JALUR GSM SHIELD MENUJU ARDUINO UNO R3

\begin{tabular}{cc}
\hline Pin LED & Pin Arduino Uno R3 \\
\hline VCC5 & Power $5 \mathrm{~V}$ \\
GND & GND \\
SVT & DIGITAL IN 7 \\
SVR & DIGITAL IN 6 \\
\hline
\end{tabular}

4. Implementasi Rangkaian Buzzer

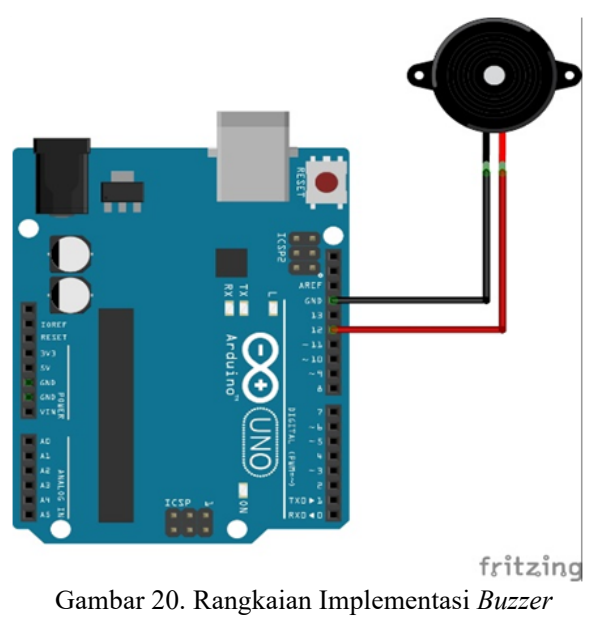

TABEL VI

JALUR BUZZER MENUJU ARDUINO UNO R3

Pin Buzzer

Pin Arduino Uno R3

$\begin{array}{cc}\text { GND } & \text { GND } \\ I N & \text { DIGITAL PWM } 12\end{array}$

\section{K. Hasil Implementasi}

Implementasi Model Prototipe Sistem Water level Otomatis berbasis Mikrokontroler Dan Sms gateway

4. Implementasi Rangkaian Gsm Shield 


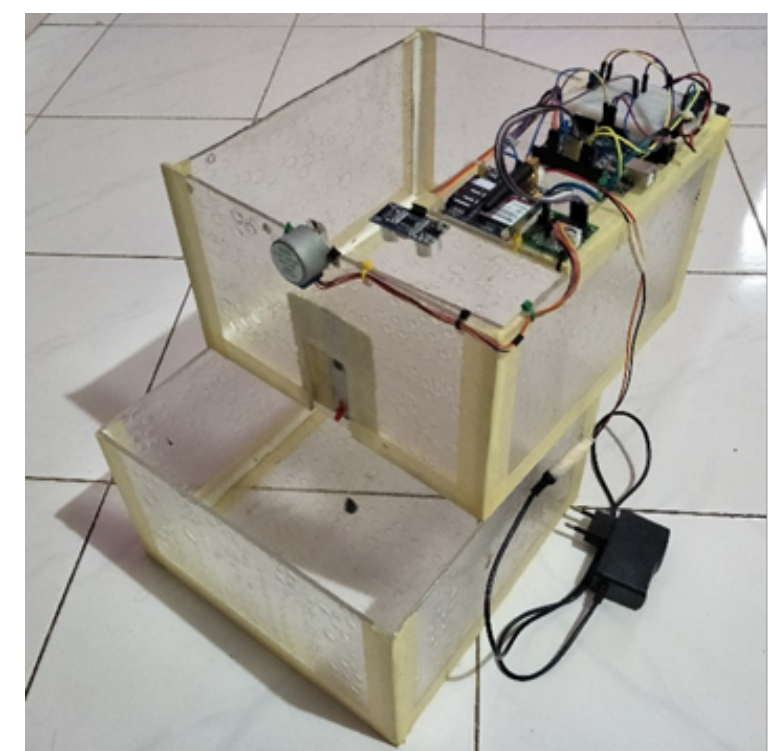

Gambar 21. Tampilan Bentuk Prototipe Pada Bagian Depan

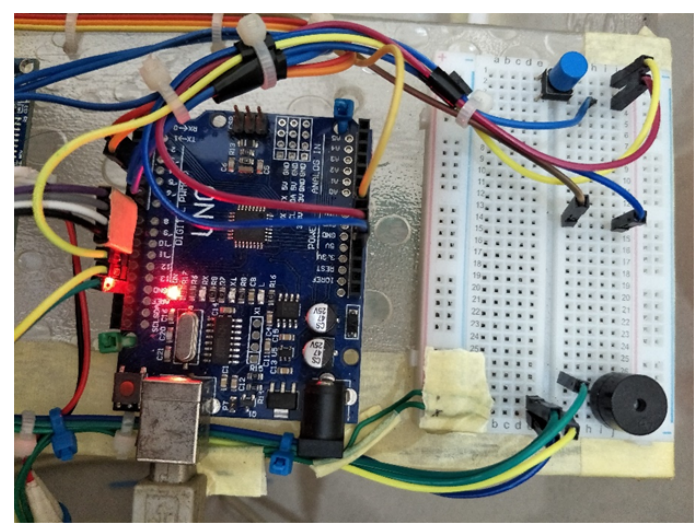

Gambar 22. Tampilan Mikrokontroler

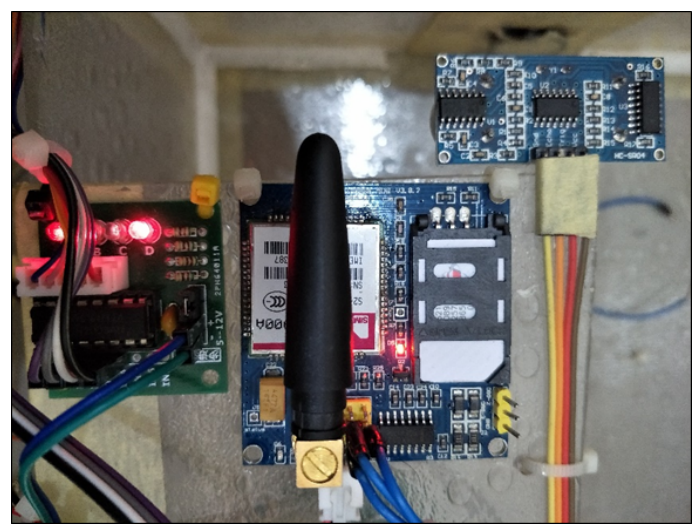

Gambar 23. Tampilan Gsm Shield \& Ultrasonic Sensor

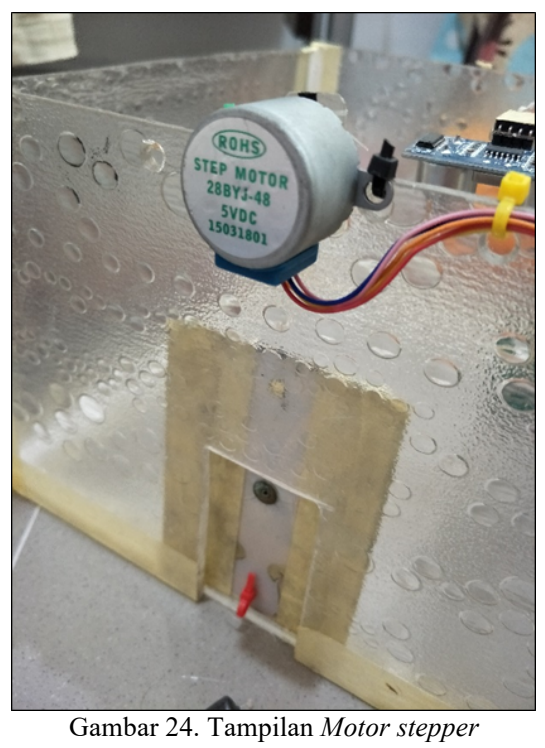

\section{K. Pengujian Sistem}

Pengujian sistem adalah kegiatan untuk melakukan pengujian terhadap sistem yang telah dirancang, yang bertujuan untuk mengetahui apakah sistem yang dibangun dapat berjalan sesuai rencana yang telah ditetapkan.[10]

TABEL VII

SPESIFIKASI PERANGKAT PROTOTIPE

\begin{tabular}{cc}
$\begin{array}{c}\text { Perangkat } \\
\text { Keras }\end{array}$ & Keterangan \\
\hline Laptop & Cpu Prosesor intel core i5, vga nvidia \\
Lenovo & geforce 930m, Ram 4GB DDR3. \\
S410p & Mid
\end{tabular}

Microcontroller Atmega 328, tegangan $5 \mathrm{~V}$, Tegangan input disarankan $7-12 \mathrm{~V}$, baras tegangan input 6-20V, pin digital

Arduino I/O ada 14 (6 pin output MPW), Pin analog input 6 , arus DC 3,3V

50Mah,Flash Memory $21 \mathrm{~Kb}$ (atmega 328), EEPROM $1 \mathrm{~Kb}$ (Atmega 328). Clock $16 \mathrm{Mhz}$

Sensor

Ultrasonic

1 buah

Sim900a

Buzzer

Motor

stepper

Adapter 5V

1 buah (Menggunakan input adapter dengan tegangan daya $5 \mathrm{~V}$ )

1 buah

1 buah (Menggunakan input adapter dengan tegangan daya $5 \mathrm{~V}$ )

2 buah

\section{KESIMPULAN}

Bab penutup bertujuan mengenai kesimpulan dari pembahasan proses alat yang dibuat sesuai dengan identifikasi masalah. Berdasarkan hasil implementasi Prototipe Sistem 
Water level Otomatis berbasis Mikrokontroler Dan Sms gateway dapat disimpulkan sebagai berikut:

1. Sistem Water level Otomatis berbasis Mikrokontroler Dan Sms gateway ini, untuk mempermudah tugas manusia dalam memantau tingkat ketinggian air

2. Prototipe water level otomatis ini dibuat menggunakan bahasa pemrograman arduino.

3. Sistem Water level Otomatis berbasis Mikrokontroler Dan Sms gateway ini berfungsi saat adanya aktivitas pengukuran ketinggian air

4. Sistem ini dibuat untuk mendeteksi ketinggian air dalam penampungan dan mengontrol ketinggiannya dengan sensor ultrasonic

5. Sistem ini menyampaikan informasi peringatan dini melalui sms

\section{REFERENSI}

[1] Basuki, Awan Pribadi, Membangun Aplikasi SMS Gateway Berbasis Web Dengan Codeigniter \& bootstrap,Yogyakarta, lokomedia, 2017

[2] Kadir, Abdul, Pemrograman Arduino \& Android Menggunakan APP Inventor, Jakarta : PT Elex Komputindo, 2017.

[3] Kadir, Abdul, Buku Pintar Pemograman Arduino, MediaKom, Yogyakarta, 2015,

[4] Dinata, Yuwono Marta, Arduino Itu Pintar, Jakarta : PT. Elex Media Komputindo, 2016.

[5] Setiyo, Muji, Listrik dan Elektronika Dasar Otomotif (Basic Automotive Electricity and Electronics), Magelang: Umimma Press. 2017.

[6] Arinta, Widyaningtiyas, Sistem Informasi Akademik Berbasis Sms Gateway Menggunakan Metode Prototype, [Universitas Dian Nusawantoro, Fakultas Ilmu Komputer, 2014]

[7] Santoso, Hari, Panduan Praktis Arduino untuk Pemula, Trenggalek : www.elangsakti.com, 2016.

[8] Roger Pressman, Rekayasa Perangkat Lunak Pendeketan Praktisi, Andi, Yogyakarta, 2012

[9] Maiyana, Efmi.Pemanfaatan Android Dalam Pernacangan Aplikasi Kumpulan Doa, Jurnal AMIK Bukit Tinggi, Sumatera Barat, 2018.

[10] Rizky, Konsep Dasar Rekayasa Perangkat Lunak, 2011, PT Prestasi Pustakaraya, jakarta 